\title{
Eficiência de utilização da energia alimentar para a produção de bezerros em vacas Nelore e mestiças ${ }^{1}$
}

\section{Carlos Augusto de Alencar Fontes ${ }^{2}$, Vítor Corrêa de Oliveira ${ }^{3}$, João Gomes de Siqueira ${ }^{4}$, Alberto Magno Fernandes ${ }^{5}$, Nivaldo de Faria Sant'Ana ${ }^{6}$, Thiago Vasconcelos Melo ${ }^{3}$}

\author{
${ }^{1}$ Projeto parcialmente financiado pela FAPERJ e pelo CNPq. \\ 2 LZNA/CCTA/UENF. Bolsista do CNPq. \\ ${ }^{3}$ Mestrando em Produção Animal - LZNA/CCTA/UENF. \\ ${ }^{4}$ Médico Veterinário, D.Sc. \\ ${ }^{5}$ LZNA/CCTA/UENF. \\ ${ }^{6}$ Doutorando em Produção Animal - LZNA/CCTA/UENF.
}

RESUMO - Objetivou-se avaliar a eficiência de conversão da matéria seca (MS) e da energia metabolizável (EM) da dieta em ganho de peso e em peso de bezerro desmamado por vaca. Utilizaram-se 13 vacas Nelore, 13 mestiças F1 Simental $\times$ Nelore (SN) e 13 F1 Limousin $\times$ Nelore (LN) com 5 a 9 anos de idade e suas respectivas crias. Entre 15 e 210 dias pós-parto, as vacas foram mantidas em baias individuais, juntamente com os bezerros. Utilizaram-se rações contendo, na MS, 30\% de concentrado e $70 \%$ das silagens de milho e sorgo na primeira e segunda metades do período experimental, respectivamente. O conteúdo de energia metabolizável das dietas foi obtido utilizando-se o fator 0,82 na conversão da energia digestível, determinada experimentalmente, em energia metabolizável. A produção de leite foi determinada mensalmente utilizando-se o método da diferença de peso dos bezerros. A eficiência foi avaliada considerando as relações: kg de bezerro desmamado e kg de ganho de peso de bezerro por kg de MS; ou por Mcal de EM ingeridos pela vaca; ou pelo par vaca/bezerro no período de lactação: ou foram estimadas para todo o ano. Foi ainda considerada a relação peso do bezerro/peso da vaca (PB/PV) à desmama. As vacas mestiças apresentaram maior eficiência de conversão da MS e da energia alimentar em peso de bezerro desmamado e em ganho de peso de bezerro. Apresentaram ainda as mais elevadas relações PB/PV à desmama. Os dois grupos de mestiças não diferiram quanto à eficiência. A utilização de matrizes obtidas por cruzamento entre bovinos de raças européias e bovinos Nelore possibilita elevar a eficiência do sistema na fase de cria.

Palavras-chave: conversão da energia, conversão da matéria seca, Limousin, Simental

\section{Efficiency of conversion of feed energy for the production of calves by Nellore and crossbred cows}

ABSTRACT - The objective was to evaluate the efficiency of conversion of dry matter (DM) and metabolizable energy (ME) of the diet on weight gain and weight of calf weaned per cow. A total of 13 Nellore, 13 crossbred $\mathrm{F}_{1}$ Simental $\times$ Nellore (SN) and 13 F1 Limousin $\times$ Nellore (LN) cows with 5 to 9 years of age and their offspring was used. Between 15 and 210 days post calving, the cows were kept in individual stalls, with the calves. Diets contained 30:70\% (\% DM) concentrate to corn or sorghum silages ratio, in the first and second half of the experimental period, respectively. The metabolizable energy content of the diet was obtained using the 0.82 factor in the conversion of digestible energy, experimentally determined, in metabolizable energy. The milk production was determined monthly using the calf weigh-suckle-weigh method. The efficiency was evaluated considering the ratios: $\mathrm{kg}$ of calf weaned and $\mathrm{kg}$ weight gain of calf per $\mathrm{kg}$ DM, or by Mcal of EM consumed by the cow, or by cow/calf pair in the period of lactation or were estimated for all the year. The relationship of calf weight/weight of the cow $(\mathrm{CP} / \mathrm{LW})$ at weaning was also considered. The crossbred cows showed higher efficiency of conversion of the DM and the feed energy in weight of weaned calf and in weight gain of calf. They showed also the highest relations CP/LW at weaning. The two crossbred groups did not differ on the efficiency. The use of matrices obtained by crossing European breeds and Nellore cattle enables raising the efficiency of cow-calf enterprise.

Key Words: dry matter conversion, energy conversion, Limousin, Simmental

\section{Introdução}

A eficiência produtiva do rebanho bovino de corte na fase de cria pode ser definida de acordo com o sucesso de conversão da energia alimentar em peso de bezerro desmamado (Jenkins \& Ferrell,1992). Entretanto, conforme salientaram Klosterman et al. (1968), a fração da energia ingerida convertida no produto bezerro é muito pequena em relação

Este artigo foi recebido em 1/3/2007 e aprovado em 13/3/2008.

Correspondências devem ser enviadas para cafontes@uenf.br. 
à exigência energética anual de mantença da vaca. Em estudos para caracterização das raças de corte, alguns autores concluíram que existem diferenças na eficiência bioeconômica entre raças e grupos mestiços (Jenkins et al., 1991; Jenkins \& Ferrell, 1994; Jenkins \& Ferrell, 2004), enquanto outros não observaram essas diferenças (Holloway et al., 1975; Bowden, 1980).

Raças européias de grande porte ou de elevado potencial leiteiro têm sido introduzidas em programas de cruzamento com o objetivo de elevar a eficiência na fase de cria. Gregory \& Cundiff (1980) mostraram que a heterose em programas de cruzamento contínuo pode aumentar em 20\% o peso de bezerro desmamado por vaca. Em estudo posterior, Jenkins \& Ferrell (2004) compararam grupos de vacas mestiças obtidas por cruzamento de matrizes Hereford e Angus com touros Bos indicus e Bos taurus de raças de corte adaptadas ao meio tropical e concluíram que as vacas filhas de touros Bos indicus produziram mais leite e tiveram maior eficiência nutricional; suas progênies, embora tivessem menor peso ao nascer, apresentaram maiores ganhos de peso e pesos ajustados à desmama. Jenkins \& Ferrell (1994) conduziram um estudo com nove raças bovinas, diferentes quanto ao porte e ao potencial leiteiro, e verificaram efeito de interação de raça e nível nutricional. As raças de menor porte ou com menor produção de leite converteram com maior eficiência a energia alimentar em peso de bezerro em condição de baixa oferta de alimento, mas foram menos eficientes que as raças de grande porte ou alto potencial leiteiro em condição de alta oferta de alimento.

Alguns trabalhos têm sido conduzidos no Brasil enfocando a eficiência de vacas de corte zebuínas e mestiças (Euclides Filho et al., 1995; Calegare, 2004), entretanto, há ainda grande carência de informações sobre o assunto, necessárias à formulação de programas consistentes de cruzamento.

Este trabalho foi conduzido com o objetivo de avaliar a eficiência de conversão da matéria seca e da energia metabolizável da dieta em peso de bezerro por vacas Nelore e mestiças (F1 Simental × Nelore e F1 Limousin $\times$ Nelore).

\section{Material e Métodos}

A pesquisa foi realizada na Universidade Estadual do Norte Fluminense Darcy Ribeiro - UENF, em Campos dos Goytacazes, Rio de Janeiro. Foram utilizadas 39 vacas adultas recém-paridas, com 5 e 9 anos de idade, 13 de cada um dos grupos genéticos: Nelore $(\mathrm{N})$, F1 Simental $\times$ Nelore $(\mathrm{SN})$ e F1 Limousin $\times$ Nelore $(\mathrm{LN})$ e seus bezerros, filhos de touros Nelore, Simental e Brahmam, respectivamente, selecionadas em rebanhos comerciais da região. Procurou-se obter equilíbrio quanto à idade, ao tempo de gestação, ao porte e ao escore de condição corporal nos três grupos genéticos. Durante o período experimental, as vacas foram mantidas confinadas juntamente com as crias em baias individuais, com área de $12 \mathrm{~m}^{2}$, metade coberta com telhas de amianto. Na extremidade de cada baia oposta ao cocho de alimentação da vaca, instalou-se um cocho protegido, em área anexa de $1,8 \mathrm{~m}^{2}$, com acesso apenas do bezerro.

As vacas foram transportadas para as dependências da universidade aproximadamente um mês antes da data prevista para o parto e foram mantidas em piquetes de capimelefante (Pennisetum purpureum CV. Napier), em pastejo rotativo, onde ocorreram os partos. Aproximadamente 15 dias após a data individual do parto, a vaca e a cria foram transferidas para as baias individuais, onde foram mantidas até o bezerro atingir 210 dias de idade. A ração experimental foi introduzida paulatinamente, fornecendo-se durante a primeira semana capim-elefante sem picar, em quantidades decrescentes.

O arraçoamento das vacas foi realizado de forma a atender às exigências individuais para mantença e produção de leite. As exigências líquidas de energia para mantença (ELm) foram obtidas considerando a relação 77 kcal de ELm por unidade de tamanho metabólico (UTM). Os valores obtidos foram posteriormente acrescidos de $20 \%$, por se tratar de vacas em lactação (NRC, 2000). A exigência líquida individual de energia para lactação (ELl) foi obtida considerando o nível de produção de leite da vaca e o equivalente calórico de 0,72 Mcal/kg de leite(NRC, 2000). No cálculo das exigências de energia metabolizável, considerou-se que vacas de corte utilizam a energia metabolizável para lactação com a mesma eficiência da mantença (NRC, 2000).

Foram utilizadas duas rações completas contendo 70\% de volumoso e $30 \%$ de concentrado na MS. Na ração 1, fornecida na primeira metade do experimento, utilizou-se silagem de milho como volumoso e, na ração 2 , fornecida na segunda metade do experimento, utilizou-se silagem de sorgo (Tabela1). Juntamente com a ração, foi fornecida diariamente a cada vaca uma mistura de $50 \mathrm{~g}$ de $\mathrm{NaCl}$ com 50 g de suplemento mineral, contendo 9\% de Ca; 6\% de P; 2,5\% de S; 21,7\% de Na; 0,25\% de Zn, 0,15\% de Cu; 0,018\% de I; $0,010 \%$ de Co; 0,002\% de Se; e 0,06\% de Fe.

A quantidade de ração a ser oferecida inicialmente a cada vaca foi calculada de acordo com os teores estimados de energia metabolizável das rações, considerando as exigências descritas pelo NRC (2000). Em seguida, utilizando-se a equação de Garrett, apresentada pelo NRC (2000), foram estimados os conteúdos de energia líquida para mantença e ganho das rações e determinados os coeficientes de 
utilização da energia metabolizável para a mantença $(\mathrm{Km})$. Posteriormente, foram determinadas as quantidades de ração necessárias para suprir $100 \%$ das exigências individuais de energia metabolizável das vacas, que atenderam, ao mesmo tempo, às exigências de proteína degradada no rúmen e às exigências de proteína metabolizável das vacas.

As quantidades individuais de ração oferecidas às vacas foram ajustadas a cada 30 dias, considerando seu peso corporal e sua produção de leite. Além disso, ajustes foram feitos de acordo com as variações no teor de MS da silagem, buscando-se manter constantes as proporções concentrado:volumoso.

Os valores reais de ingestão de EM das vacas e dos bezerros foram calculados, posteriormente, com base nos conteúdos de EM das duas rações, determinados experimentalmente no decorrer da pesquisa e utilizados nos cálculos de eficiência energética de produção de bezerros.

Aproximadamente aos 90 dias de idade, os bezerros receberam a ração das mães em cochos protegidos (creep feeding). A quantidade fornecida foi limitada a $1 \mathrm{~kg}$ de MS/ dia ou a $30 \%$ das exigências nutricionais, o que possibilitou avaliar a influência do nível de produção de leite das vacas sobre o desenvolvimento das crias e sobre a eficiência energética de produção dos bezerros.

A ração foi fornecida uma vez ao dia, às $9 \mathrm{~h}$, registrando-se as quantidades individuais de alimento oferecidas, assim como das sobras, que foram removidas e pesadas pela manhã, antes do trato, para determinação dos consumos individuais das vacas e dos bezerros. O concentrado, a silagem e a mistura mineral destinados a cada vaca foram misturados diretamente no cocho, no momento do fornecimento.

Diariamente, coletaram-se uma amostra da silagem e amostras individuais das sobras, correspondentes a $10 \%$ do total, constituindo amostras compostas de silagem, a cada semana, e amostras proporcionais das sobras, a cada 28 dias. A ração concentrada foi amostrada a cada mistura de ingredientes.

Durante o período experimental, foram conduzidos dois ensaios de digestibilidade, na primeira e segunda metade do experimento, para determinação das digestibilidades da MS e energia das duas rações utilizadas, o que possibilitou estimar os consumos individuais de energia digestível (ED) das vacas e dos bezerros. Os coeficientes de digestibilidade foram determinados utilizando-se as informações individuais de consumo e excreção fecal de MS e energia bruta (EB) das vacas, referentes a um período de sete dias em cada ensaio. Amostras fecais individuais foram coletadas diretamente no reto, duas vezes ao dia, entre $7 \mathrm{~h}$ e $9 \mathrm{~h}$ e entre 16 e $18 \mathrm{~h}$. A excreção fecal foi estimada utilizando-se o indicador interno fibra em detergente neutro indigerível (FDNi), cujos conteúdos foram obtidos determinado-se os teores de fibra em detergente neutro (FDN) do material residual após incubação in vitro do alimento, das sobras e das fezes durante144 horas (Cochran et al., 1986).

Os conteúdos de energia bruta do alimento, das sobras e das fezes individuais foram determinados em bomba calorimétrica e as quantidades ingeridas de energia bruta e matéria seca foram obtidas deduzindo-se as quantidades contidas nas sobras. O conteúdo de energia metabolizável da ração foi estimado utilizando-se o fator 0,82 na conversão da energia digestível em energia metabolizável (NRC, 2000).

Mensalmente, foi estimada a produção de leite de cada vaca utilizando-se o método de diferença entre os pesos dos bezerros tomados antes e após a amamentação (Cundiff et al., 1974). O peso vivo em jejum (PVJ) das vacas e dos bezerros foi mensurado no início e ao fim do experimento e a cada mês, ao determinar a produção de leite. Antes da

Tabela 1 - Composição das rações experimentais

\begin{tabular}{|c|c|c|c|c|c|c|c|c|}
\hline \multirow[b]{3}{*}{ Ingrediente } & \multirow[b]{3}{*}{ Teor de $\mathrm{MS}^{1}$} & \multicolumn{7}{|c|}{ Composição na MS } \\
\hline & & \multirow[b]{2}{*}{ Proporção } & \multirow[b]{2}{*}{$\mathrm{PB}^{1}$} & \multirow{2}{*}{$\begin{array}{c}\% \\
\text { FDN }^{1} \\
\end{array}$} & \multirow[b]{2}{*}{$\mathrm{Ca}^{2}$} & \multirow[b]{2}{*}{$\mathrm{P}^{2}$} & \multicolumn{2}{|c|}{ Mcal/kg } \\
\hline & & & & & & & $\mathrm{ED}^{1}$ & $\mathrm{EM}^{1}$ \\
\hline & \multicolumn{8}{|c|}{ Ração 1} \\
\hline Silagem milho & 30,9 & 70,0 & 6,9 & 55,8 & 0,31 & 0,27 & - & - \\
\hline Concentrado & 79,2 & 30,0 & 23,9 & 16,8 & 0,08 & 0,53 & - & - \\
\hline \multirow[t]{2}{*}{ Ração completa } & 45,4 & 100,0 & 12,0 & 44,1 & 0,24 & 0,30 & 2,77 & 2,27 \\
\hline & \multicolumn{8}{|c|}{ Ração 2} \\
\hline Silagem de sorgo & 26,2 & 70,0 & 6,5 & 50,1 & 0,40 & 0,20 & - & - \\
\hline Concentrado & 79,2 & 30,0 & 23,9 & 16,8 & 0,08 & 0,53 & - & - \\
\hline Ração completa & 42,1 & 100,0 & 11,7 & 40,1 & 0,30 & 0,30 & 2,70 & 2,21 \\
\hline
\end{tabular}

${ }^{1}$ Valores determinados experimentalmente.

2 Valores obtidos em tabela (NRC, 2000). 
pesagem, as vacas foram mantidas em jejum durante 16 horas, com acesso à água.

A eficiência produtiva das vacas no período prédesmama foi expressa inicialmente em ganho de peso do bezerro durante o período de aleitamento em relação ao consumo de energia metabolizável ou matéria seca pela vaca ou pelo par vaca/bezerro, na forma de alimento sólido, no período de aleitamento.

Além da energia metabolizável consumida pela vaca ou pelo par vaca/bezerro, computou-se também a energia disponibilizada pela mobilização de reservas corporais da vaca, disponível para produção de leite. De acordo com o NRC (2000), 1 kg de tecido corporal mobilizado corresponde a 5,82 Mcal de energia, utilizados pela vaca de corte com 80\% de eficiência para mantença e/ou produção de leite, equivalendo a 4,656 Mcal de energia líquida (EL). Como a perda de $1 \mathrm{~kg}$ de PVJ equivale a 0,956 kg de perda de tecido corporal da vaca (NRC, 2000), considerou-se neste trabalho que foram disponibilizados para produção de leite 4,45 Mcal de EL por kg de PVJ perdido. Na conversão de energia líquida em energia metabolizável, utilizou-se o $\mathrm{K}_{\mathrm{m}}$ médio estimado para as duas rações.

Estimou-se ainda eficiência de produção de $1 \mathrm{~kg}$ de bezerro desmamado, considerando o consumo estimado de energia metabolizável da vaca durante todo o ano. Neste caso, além do consumo de energia metabolizável verificado durante o período de aleitamento, foram acrescentados os consumos de energia metabolizável correspondentes à exigência de EM de mantença da vaca durante o período pósdesmama, em relação ao seu peso vivo, e à exigência de EM adicional correspondente ao terço final de gestação, segundo o NRC (2000).

De forma semelhante, calculou-se o índice de conversão da MS consumida pela vaca durante o ano em peso de bezerro desmamado, admitindo-se que, no período pósdesmama e no terço final de gestação, a vaca recebeu ração com conteúdo de EM igual à da ração fornecida no período pré-desmama. Os cálculos desses dois índices de eficiência foram feitos de duas formas: considerando ou não a energia disponibilizada pela mobilização de reservas corporais da vaca durante o período de amamentação. Essa eficiência foi estimada considerando taxa de desmame de 100\% (cada vaca desmamando um bezerro).

Em virtude das limitações impostas pelo manejo experimental, não foi possível a detecção sistemática dos cios nem a adoção de uma estação de monta durante o período experimental considerando diferenças potenciais entre grupos genéticos quanto à fertilidade nos cálculos da eficiência de conversão da energia alimentar em peso/ ganho de peso de bezerro. Para possibilitar uma rotina comum aos três grupos que viabilizasse a utilização da inseminação artificial, as vacas foram submetidas a um protocolo de sincronização/indução de cios e inseminação artificial em tempo fixo depois de períodos semelhantes pós-parto (145,3 \pm 11,6, 148,8 \pm 20,7 e 147,0 \pm 9,8 dias para vacas as Nelore, $\mathrm{SN}$ e LN, respectivamente).

Utilizou-se o protocolo PEPE, recomendado por Barros \& Ereno (2004), que consistiu na administração de 2,0 mg de benzoato de estradiol, via intramuscular, no momento da inserção do dispositivo intravaginal (Dia 0) e da aplicação de Prostaglandina F2 $\alpha$ (PGF2 $\alpha$ ) no momento de remoção do dispositivo intravaginal (Dia 8) e 1,0 mg de BE (via intramuscular) 24 horas mais tarde. A inseminação artificial foi realizada 30 a 36 horas após a última administração de benzoato de estradiol. Portanto, foram utilizados no protocolo os hormônios progesterona-estrógenoprostalandina-estrógeno.

As análises estatísticas referentes à produção de leite foram feitas utilizando-se a metodologia proposta por Jenkins \& Ferrell (1992), descrita detalhadamente por Oliveira et al. (2007).

Nas análises estatísticas, empregou-se a metodologia de mínimos quadrados do procedimento GLM do SAS. Os dados referentes ao peso das vacas ao parto e à desmama e às variáveis relacionadas à eficiência das vacas foram analisados de acordo com o modelo estatístico que incluiu os efeitos do grupo genético, da idade da vaca e do erro aleatório. Nas análises referentes aos pesos dos bezerros ao nascer, à desmama e ao ganho de peso dos bezerros, utilizou-se modelo incluindo os efeitos de grupo genético, sexo do bezerro, interação de grupo genético e sexo dos bezerros, co-variável idade da vaca e do erro aleatório. As comparações entre os três grupos genéticos foram feitas por meio de contrastes ortogonais entre as vacas Nelore e as mestiças, em conjunto, e entre os dois grupos de mestiças.

\section{Resultados e Discussão}

Informações detalhadas sobre o consumo diário de MS durante o período de aleitamento da vaca (CMS/V) e do par vaca + bezerro $(\mathrm{CMS} / \mathrm{V}+\mathrm{B})$; o consumo de EM durante o período de aleitamento da vaca (CEM/V) e do par vaca + bezerro (CEM/V+B); o consumo anual estimado de MS (CMSA/V) e de EM (CEMA/V) da vaca; o peso vivo da vaca ao parto (PVP) e à desmama (PVD); o peso do bezerro à desmama ajustado para 210 dias de idade; e a produção total de leite da vaca em 210 dias de lactação (Pl); são descritas por Oliveira et al. (2007). Nesta pesquisa, para todas as variáveis consideradas (Tabela 2), os valores obtidos com 
as vacas Nelore foram menores $(\mathrm{P}<0,005)$ que os valores médios dos dois grupos de vacas mestiças tomados em conjunto, conforme indicaram os contrastes ortogonais entre vacas Nelore e mestiças $(\mathrm{N} \times \mathrm{M})$. Os dois grupos de vacas mestiças só diferiram entre si quanto à produção total de leite na lactação $(\mathrm{P}<0,005)$, uma vez que as vacas $\mathrm{SN}$ produziram mais leite que as LN.

Os resultados evidenciaram influência do nível de produção de leite da vaca sobre o peso do bezerro à desmama. As vacas Nelore produziram menos leite que as mestiças e desmamaram bezerros mais leves, enquanto as vacas SN tiveram produções de leite mais elevadas e desmamaram bezerros mais pesados.

Os maiores consumos de MS e EM das vacas mestiças em relação às Nelore estão relacionados aos seus maiores pesos corporais e às mais altas produções de leite.

Buscou-se atender 100\% das exigências totais de energia das vacas, de acordo com o NRC (2000), e o consumo de EM estimado situou-se um pouco abaixo da meta, correspondendo a 95,0; 96,0 e 99.0\% das exigências de vacas Nelore, SN e LN, respectivamente. As diferenças podem ser atribuídas às variações na produção de leite dos animais e ao conteúdo de MS da silagem no período experimental. O consumo de energia ligeiramente abaixo das exigências contribuiu para o menor peso corporal à desmama das vacas dos três grupos genéticos em relação ao dia subseqüente ao parto (Tabela 2). Todas as vacas perderam peso na primeira metade do período de aleitamento e ganharam peso na segunda metade desse período, mas não recuperaram o peso que apresentavam logo após o parto, conforme detalhado por Oliveira et al. (2007). As vacas SN, que apresentaram a maior produção total de leite, perderam mais peso, enquanto as Nelore, com produção mais baixa, foram as que perderam menos peso. As vacas $L N$ tiveram produção de leite e perda de peso intermediárias.

De forma semelhante a este trabalho, os resultados obtidos por Calegare (2004) indicaram pesos à desmama menores que aqueles observados imediatamente após o parto em vacas Nelore e mestiças $F_{1}$ Canchim-Nelore, $\mathrm{F}_{1}$ Angus-Nelore e $\mathrm{F}_{1}$ Simental-Nelore, embora as vacas tenham sido alimentadas com dieta adequada para manter o peso corporal constante. A mesma tendência foi registrada por Jenkins et al. (2000), que forneceram a vacas de corte mestiças F1 de oito grupos genéticos, três níveis de energia, incluindo um nível de energia marginal, um nível normal e um nível alto, e verificaram nas vacas de todos os grupos genéticos e níveis nutricionais pesos corporais à desmama menores que os obtidos logo após o parto. A diferença média foi de $83 \mathrm{~kg}$ para as vacas que receberam o nível de energia mais baixo, 47 kg para o nível intermediário e $27 \mathrm{~kg}$ para aquelas que receberam o nível alto de energia.

Uma pequena parcela da diferença de peso entre o parto e a desmama observada nas vacas deste trabalho e dos trabalhos supracitados pode estar relacionada à redução do peso do trato genital no período puerperal (aproximadamente $9 \mathrm{~kg}$, segundo informações de Ferrell, 1991).

Além disso, a mudança de regime alimentar entre o parto e a desmama - as vacas saíram do pasto para o confinamento, onde receberam ração com maior densidade energética, contendo $30 \%$ de concentrado - possivelmente provocou redução do peso de digesta do trato gastrintestinal (TGI). Neste sentido, Fontes et al. (2007) relataram que a transferência de novilhos (com peso inicial de $249 \mathrm{~kg}$ ) do

Tabela 2 - Níveis de probabilidade para o erro tipo I associados aos contrates ortogonais entre vacas ou progênies de vacas Nelore e mestiças $(\mathrm{N} \times \mathrm{M})$ e entre vacas ou progênies de vacas F1 Nelore $\times$ Simental e F1 Nelore $\times$ Limousin $(\mathrm{SN} \times \mathrm{LN})$ para características relacionadas ao peso corporal e à produção de leite

\begin{tabular}{|c|c|c|c|c|c|c|}
\hline \multirow[b]{2}{*}{ Variável } & \multicolumn{2}{|c|}{$\begin{array}{l}\text { Nível de probabilidade } \\
\text { para os contrastes }\end{array}$} & \multicolumn{3}{|c|}{$\begin{array}{c}\text { Média de quadrados mínimos } \\
\text { e erros-padrão }\end{array}$} & \multirow[b]{2}{*}{ CV (\%) } \\
\hline & $\mathrm{N} \times \mathrm{M}$ & $\mathrm{SN} \times \mathrm{LN}$ & $\mathrm{N}$ & $\mathrm{SN}$ & $\mathrm{LN}$ & \\
\hline CMS/V, kg/dia & $<0,0001$ & 0,0970 & $7,4 \pm 0,24$ & $9,0 \pm 0,26$ & $8,4 \pm 0,24$ & 10,53 \\
\hline CEM/V, Mcal/dia & $<0,0001$ & 0,0970 & $16,5 \pm 0,52$ & $20,1 \pm 0,58$ & $18,7 \pm 0,54$ & 10,53 \\
\hline $\mathrm{CMS} / \mathrm{V}+\mathrm{B}, \mathrm{kg} / \mathrm{dia}$ & 0,0003 & 0,1084 & $7,8 \pm 0,24$ & $9,3 \pm 0,26$ & $9,7 \pm 0,24$ & 10,23 \\
\hline $\mathrm{CEM} / \mathrm{V}+\mathrm{B}, \mathrm{Mcal} / \mathrm{dia}$ & 0,0003 & 0,1084 & $17,4 \pm 0,54$ & $20,9 \pm 0,59$ & $19,5 \pm 0,54$ & 10,23 \\
\hline CMSA/V, kg/dia & $<0,0001$ & 0,0508 & $6,8 \pm 0,15$ & $8,1 \pm 0,16$ & $7,6 \pm 0,15$ & 7,01 \\
\hline CEMA/V, kg/dia & $<0,0001$ & 0,0508 & $15,4 \pm 0,33$ & $18,1 \pm 0,36$ & $17,2 \pm 0,33$ & 7,01 \\
\hline PVP, kg & $<0,0001$ & 0,4221 & $377,9 \pm 12,38$ & $465,1 \pm 13,46$ & $450,2 \pm 12,38$ & 10,40 \\
\hline PVD, kg & $<0,0001$ & 0,5486 & $346,2 \pm 10,38$ & $400,1 \pm 11,29$ & $409,4 \pm 10,38$ & 9,74 \\
\hline $\mathrm{PBzD}_{210}, \mathrm{~kg}$ & $<0,0001$ & 0,2379 & $138,8 \pm 6,50$ & $187,1 \pm 7,40$ & $175,5 \pm 6,20$ & 13,11 \\
\hline $\mathrm{PL}_{210}, \mathrm{~kg}$ & $<0,0001$ & 0,0006 & $776,6 \pm 68,60$ & $1.422,5 \pm 72,10$ & $1.030,8 \pm 68,4$ & 23,81 \\
\hline
\end{tabular}

* em que: CMS/V - consumo de matéria seca (MS) da vaca durante o período de aleitamento; CEM/V - consumo de energia metabolizável (EM) da vaca durante o período de aleitamento; CMS/V+B - consumo de MS do par vaca + bezerro durante o período de aleitamento; CEM/V+B - consumo de EM do par vaca + bezerro durante o período de aleitamento; CMSA/V - consumo diário médio estimado de MS da vaca durante o ano; CEMA/V - consumo diário médio estimado de EM da vaca durante o ano; PVP - peso da vaca ao parto; PVD - peso da vaca à desmama; $\mathrm{PBzD}_{210}-$ peso do bezerro à desmama corrigido para 210 dias de idade; $\mathrm{PL}_{210}$ - produção de leite total da vaca em 210 dias de lactação. 
pasto para o confinamento resultou na redução de $12,4 \mathrm{~kg}$ no conteúdo de digesta do trato gastrintestinal após 28 dias de consumo de ração com 56\% de concentrado.

Parte da redução de peso observada pode não representar perda de tecido corporal. Essa perda real de peso não pôde ser determinada, mas foi maior nas vacas $\mathrm{SN}$, com maior aptidão leiteira. O NRC (2000) informa que a exigência de energia de mantença de vacas com maior aptidão leiteira é mais elevada que daquelas com menor aptidão e que vacas zebuínas têm menor exigência que as F1 Europeu $\times$ Zebu. Neste trabalho, adotou-se para todos os grupos o valor único de exigência de 77 kcal/UTM, acrescido de 20\%, por se tratar de vacas em lactação (NRC, 2000), o que pode ter subestimado as exigências de mantença.

Admitindo-se que toda a diferença de peso entre o parto e a desmama correspondeu à perda real de tecido corporal e adotando-se o equivalente calórico de 4,45 Mcal de EL por kg de PVJ perdido, a perda de peso das vacas dos três grupos corresponderia à mobilização de energia equivalente a 6,4 10,2 e 7,0\% das exigências energéticas totais das vacas Nelore, SN e LN, respectivamente, durante o período de aleitamento. Este aporte de energia por mobilização corporal foi considerado em um dos cálculos da eficiência das vacas na produção de bezerros.

Os resultados obtidos para a eficiência de conversão da MS e da EM consumidas pela vaca ou pelo par vaca/ bezerro, em peso de bezerro, para as vacas dos três grupos genéticos, considerando a energia liberada pela mobilização de tecidos corporais da vaca durante o período de aleitamento (Tabela 3), estão de acordo com os reportados por Klosterman et al. (1968), comprovando que, em um rebanho de cria, a quantidade de energia ingerida que retorna como produto no bezerro é muito pequena, uma vez que grande parte da energia disponível é utilizada para atender à mantença da vaca durante 12 meses e à mantença do bezerro. Neste trabalho, o cruzamento entre bovinos de raças Bos indicus e Bos taurus elevou a produtividade do rebanho de cria. As vacas mestiças foram mais eficientes $(\mathrm{P}<0,05)$ que as Nelore em todos os critérios de avaliação considerados e apresentaram melhores relações entre os consumos de MS e EM e o ganho de peso ou peso de bezerro desmamado. Quando considerados a relação entre o ganho de peso do bezerro até a desmama e o consumo de EM pelo par vaca/bezerro, as vacas mestiças foram $17,5 \%$ mais eficientes que as Nelore.

Os dois grupos de vacas mestiças não diferiram quanto a nenhum dos indicadores de produtividade considerados, embora as vacas $\mathrm{SN}$ tenham apresentado tendência $(\mathrm{P}<0,1)$ de maior consumo de MS e EM, em virtude de sua maior
$(\mathrm{P}<0,001)$ produção de leite. Os valores de conversão da EM ingerida pelo par vaca/bezerro em ganho de peso de bezerro - 34,72; 30,18 e 29,43 Mcal de EM por kg de ganho para as vacas Nelore, SN e LN, equivalentes à produção de 30,00, 33,64 e 34,46 g de ganho de peso de bezerro por Mcal de EM consumida pelo par vaca/bezerro - foram próximos aos relatados na literatura. Jenkins et al. (1991) realizaram experimento com grupos de vacas F1, obtidas por cruzamento de touros de sete raças européias (britânicas e continentais), diferentes quanto ao porte e potencial leiteiro, com vacas Angus ou Hereford e identificaram os grupos de acordo com a raça paterna. Os valores de eficiência encontrados, em gramas de bezerro desmamado por Mcal de EM ingerida pelo par vaca/bezerro, foram 35,8 para pais Angus ou Hereford; 35,7 para Red Poll; 35,6 para Maine Anjou; 33,1 para Chianina; 33,7 para Gelbvieh; e 34,3 para Brown Swiss. As progênies de vacas de maior porte ou aptidão leiteira tiveram maiores ganhos de peso, entretanto, as diferenças não foram suficientes para compensar as maiores exigências de energia para manutenção de peso constante das vacas. Assim, as vacas de porte médio e de potencial leiteiro moderado tenderam a ser mais eficientes.

Os indicadores de eficiência observados neste trabalho foram inferiores aos descritos por Calegare (2004) em trabalho conduzido no Brasil. Esse autor verificou para as progênies de vacas Nelore, F1 Canchim-Nelore, F1 AngusNelore e F1 Simental-Nelore, respectivamente, ganhos de peso de 40,7; 45,9; 48,5 e 45,2 g por Mcal de EM consumida pelo par vaca/bezerro. Neste trabalho, a ordem de eficiência das raças manteve-se inalterada quando considerado apenas o consumo da vaca ou o consumo do par vaca/bezerro no período de aleitamento. O fato de os bezerros dos três grupos terem recebido quantidades limitadas fixas de ração pode ter influenciado este resultado.

Ao adicionar a energia mobilizada dos tecidos, estimada considerando a perda de peso das vacas, ao consumo de energia da vaca ou do par vaca/bezerro, a ordem de eficiência dos grupos genéticos não se alterou e as variações nos resultados foram muito pequenas, o que está relacionado ao fato de a energia mobilizada representar uma fração muito pequena da energia consumida.

Quando a eficiência foi expressa em gramas de bezerro desmamado por kg de MS alimentar consumida pela vaca durante a fase de aleitamento, os valores variaram de $67 \mathrm{~g} / \mathrm{kg}$ MS para vacas Nelore a $79 \mathrm{~g} / \mathrm{kg}$ MS para vacas LN, logo, as vacas Nelore foram menos eficientes $(\mathrm{P}<0,05)$ que as mestiças. Esses valores são muito próximos aos encontrados por Jenkins \& Ferrell (2004) para vacas F1 resultantes do cruzamento Angus $\times$ Hereford $(\mathrm{AH})$ e para vacas F1 
Tabela 3 - Níveis de probabilidade para o erro tipo I associados aos contrastes ortogonais entre vacas Nelore e mestiças $(\mathrm{N} \times \mathrm{M})$ e vacas mestiças F1 Simental-Nelore e F1 Limousin-Nelore $(\mathrm{SN} \times \mathrm{LN})$ para variáveis relacionadas à eficiência alimentar

\begin{tabular}{|c|c|c|c|c|c|c|}
\hline \multirow[b]{2}{*}{ Variável } & \multicolumn{2}{|c|}{$\begin{array}{l}\text { Nível de probabilidade } \\
\text { para os contrastes }\end{array}$} & \multicolumn{3}{|c|}{$\begin{array}{l}\text { Média de quadrados mínimos } \\
\text { e erros-padrão }\end{array}$} & \multirow[b]{2}{*}{ CV (\%) } \\
\hline & $\mathrm{N} \times \mathrm{M}$ & $\mathrm{SN} \times \mathrm{LN}$ & $\mathrm{N}$ & $\mathrm{SN}$ & $\mathrm{LN}$ & \\
\hline & \multicolumn{5}{|c|}{$\begin{array}{l}\text { Eficiência em relação apenas ao consumo de MS } \\
\text { ou EM da vaca no período de lactação }\end{array}$} & \\
\hline MS/GPB, kg/kg & 0,0036 & 0,8555 & $14,74 \pm 0,62$ & $12,43 \pm 0,67$ & $12,26 \pm 0,62$ & 16,96 \\
\hline EM/GPB Mcal/kg & 0,0182 & 0,6844 & $32,97 \pm 1,40$ & $29,11 \pm 1,53$ & $28,26 \pm 1,40$ & 16,79 \\
\hline GPB/EM, g/Mcal & 0,0389 & 0,6524 & $31,69 \pm 1,40$ & $34,91 \pm 1,52$ & $35,85 \pm 1,40$ & 14,76 \\
\hline
\end{tabular}

Eficiência em função do consumo de EM da vaca em lactação e da energia da perda de peso da vaca

\begin{tabular}{|c|c|c|c|c|c|c|}
\hline EM/GPB, Mcal/kg & 0,0253 & 0,5385 & $35,50 \pm 1,76$ & $31,27 \pm 1,91$ & $29,66 \pm 1,76$ & 19,64 \\
\hline GPB/EM, g/Mcal & 0,0395 & 0,4956 & $29,59 \pm 1,49$ & $32,72 \pm 1,62$ & $34,25 \pm 1,49$ & 16,71 \\
\hline & \multicolumn{6}{|c|}{$\begin{array}{c}\text { Eficiência em relação ao consumo de MS ou } \\
\text { EM da vaca em lactação e do bezerro }\end{array}$} \\
\hline MS/GPB, kg/kg & 0,0023 & 0,8989 & $15,54 \pm 0,66$ & $12,91 \pm 0,72$ & $12,79 \pm 0,66$ & 17,23 \\
\hline GPB/MS, g/kg & 0,0038 & 0,9204 & $67,00 \pm 3,05$ & $78,54 \pm 3,32$ & $79,00 \pm 3,05$ & 14,75 \\
\hline EM/GPB, Mcal/kg & 0,0113 & 0,7319 & $34,73 \pm 1,49$ & $30,18 \pm 1,62$ & $29,43 \pm 1,49$ & 17,04 \\
\hline
\end{tabular}

Eficiência em relação ao consumo de EM da vaca em lactação e do bezerro e da energia da perda de peso da vaca

\begin{tabular}{|c|c|c|c|c|c|c|}
\hline EM/GPB, Mcal/kg & 0,0168 & 0,5797 & $37,29 \pm 1,84$ & $32,37 \pm 2,00$ & $30,85 \pm 1,84$ & 19,77 \\
\hline GPB/EM, g/Mcal & 0,0249 & 0,5342 & $28,17 \pm 1,42$ & $31,61 \pm 1,55$ & $32,93 \pm 1,42$ & 16,62 \\
\hline
\end{tabular}

* em que: MS/GPB - consumo de matéria seca (MS) da vaca ou do par vaca + bezerro (kg) por kg de ganho de peso do bezerro; GPB/MS - ganho de peso do bezerro (g) por kg de MS ingerida pela vaca ou pelo par vaca+ bezerro; EM/GPB - Mcal de energia metabolizável (EM) consumida pela vaca ou pelo par vaca + bezerro (acrescida ou não da energia resultante da perda de peso da vaca) por kg de peso ganho pelo bezerro; GPB/EM - ganho de peso do bezerro, em g, por Mcal de EM consumida pela vaca ou pelo par vaca+bezerro (acrescida ou não da energia resultante da perda de peso da vaca).

obtidas pelo cruzamento de touros das raças Brahman, Tuli (Bos taurus adaptado aos trópicos) e Boran (Bos indicus adaptado aos trópicos) com vacas Angus e Hereford, respectivamente, 72,6; 88,6; 85,0 e 74,2 g/kg de MS. Esses autores concluíram que vacas F1 Bos indicus $\times$ Bos taurus foram mais eficientes que as Bos taurus $\times$ Bos taurus, resultado que pode ser atribuído ao maior nível de heterose nos cruzamentos entre animais geneticamente distantes (Gregory \& Cundify, 1999; Jenkins \& Ferrell, 2004). Resultados diferentes dos obtidos neste trabalho e daqueles relatados por Jenkins \& Ferrell (2004) foram observados por Calegare (2004), que observou ganhos de peso do bezerro durante o aleitamento de 92,5; 103,2; 110,8 e 102,8 g por kg de MS ingerida pelo par vaca/bezerro para vacas Nelore, $\mathrm{F}_{1}$ Canchim-Nelore, $\mathrm{F}_{1}$ Angus-Nelore e $\mathrm{F}_{1}$ Simental-Nelore, respectivamente.

Foram estimados também índices de eficiência globais do rebanho de cria, os quais foram computados a partir do consumo anual de MS e de EM da vaca, durante todo o ano, para mantença, lactação e gestação, o que determinou sua conversão em peso de bezerro desmamado (Tabela 4). Os valores estimados para EM/PD210 para vacas Nelore (40,54 Mcal de EM/kg de bezerro) foram maiores $(\mathrm{P}<0,01)$ que para as vacas mestiças SN (34,92) e LN (35,01 Mcal de $\mathrm{EM} / \mathrm{kg}$ ), que não diferiram $(\mathrm{P}>0,05)$ entre si, portanto, as vacas mestiças foram mais eficientes que as Nelore. Esses valores correspondem, no entanto, à eficiência na situação em que todas as vacas desmamaram um bezerro. A eficiência diminui de acordo com a taxa de desmame. Em avaliação semelhante, Davis et al. (1994) estimaram consumo anual de EM de vacas Hereford, F1 Hereford-Angus, F1 SimentalHereford, 3/4 Hereford-Simental e 3/4 Simental-Hereford em condições de exploração comercial durante dez anos. A taxa de desmama média para os cincos grupos foi de $68,2 \%$ no período. A eficiência média estimada das vacas dos cinco grupos, expressa em Mcal de energia consumida pela vaca por kg de bezerro desmamado, foi de 51,8 Mcal/kg para a taxa de desmame.

Ajustando-se os valores de taxa de desmame de 100\% para 68,2\%, obtiveram-se índices de eficiência que variam de 59,5 Mcal/kg de bezerro para vacas Nelore a 51,3 Mcal/kg para vacas LN, próximos aos encontrados por Davis et al. (1994).

Os valores estimados para $\mathrm{PD}_{210} / \mathrm{EM}$ para as vacas Nelore, SN e LN neste trabalho, correspondentes à taxa de desmame de $100 \%$, respectivamente, 25,14, 28,96 e 25,75 g 
de bezerro por Mcal de EM ingerido pela vaca durante o ano (Tabela 4), foram próximos aos estimados por Jenkins \& Ferrell (1994) como pontos de máximo para peso de bezerro desmamado por Mcal de EM ingerido pela vaca durante o ano. Esses autores forneceram a vacas mestiças de nove grupos genéticos quatro níveis de alimentação (58, 76, 93 e $111 \mathrm{~g}$ de $\mathrm{MS} / \mathrm{PV}^{0,75}$ ) e verificaram interação grupo genético × nível de nutrição. Vacas de menor porte e/ou produção de leite foram as mais eficientes em condição de baixa nutrição e vacas de maior porte e/ou produção de leite foram as mais eficientes em situação de alto nível nutricional. O ponto de máximo de cada raça foi atingido quando o desempenho reprodutivo foi ótimo. As produções de bezerro no ponto de máximo variaram entre 25 a 32 g por Mcal de energia ingerida pela vaca durante o ano.

Conforme salientado por Jenkins \& Ferrell (1994), a eficiência de conversão do alimento em peso de bezerro desmamado difere entre raças bovinas. Independentemente da raça, o nível nutricional é o fator que exerce maior influência sobre a eficiência de produção da vaca até a desmama. As raças diferem quanto aos níveis ótimos de consumo alimentar para máxima eficiência. O uso de vacas com alto nível de exigência em ambientes nutricionalmente limitantes tem efeito negativo sobre a eficiência produtiva, sobretudo por seu efeito restritivo sobre a reprodução. Animais puros ou mestiços com elevado potencial para crescimento ou produção de leite seriam mais eficientes quando os recursos alimentares não fossem limitantes.

Neste trabalho, os níveis de energia supridos às vacas foram um pouco abaixo das exigências totais de energia calculadas (95,0; 96,0 e 99,0\% para vacas Nelore, SN e LN, respectivamente). Entretanto, não foi possível medir a taxa de concepção das vacas durante uma estação de monta regular, de forma a se estimar a influência de possíveis diferenças na fertilidade entre grupos sobre a eficiência produtiva no ano seguinte. Realizou-se apenas uma inseminação artificial com tempo fixo (protocolo PEPE, recomendado por Barros \& Ereno, 2004), após períodos semelhante pós-parto (145,3, 148,8 e 147,0 dias, para vacas Nelore, SN e LN, respectivamente), o que resultou em taxas de concepção de 54,5, 58,3 e 61,5\% para os três grupos, respectivamente, as quais não diferiram entre si $(\mathrm{P}>0,05)$ pelo teste de qui-quadrado.

Essas taxas de concepção estão no intervalo esperado de 50 a 65\% de concepção, quando vacas em cio são submetidas a uma única inseminação (Barros \& Ereno, 2004). Ressalta-se, no entanto, que a sincronização de cio foi efetuada tardiamente, o que impossibilitou prever o comportamento reprodutivo das vacas dos três grupos caso a sincronização fosse feita na época recomendada, mais próxima ao parto.

O fato de os bezerros filhos das vacas com maior produção de leite terem sido mais pesados à desmama confirma as observações de Neville Jr. (1962) e Rutledge et al. (1971), que concluíram, respectivamente, que aproximadamente 66 e $60 \%$ da variância do peso do bezerro à desmama aos 205 dias podem ser atribuídos ao efeito direto da produção de leite da vaca. Alencar (1987) também verificou relação linear positiva entre a produção de leite da vaca e o peso do bezerro à desmama. Entretanto, os valores do quociente entre o ganho diário de peso do bezerro e a produção média diária de leite da vaca (GPB/PL) indicaram

Tabela 4 - Níveis de probabilidade para o erro tipo I associados aos contrastes ortogonais entre vacas Nelore e mestiças $(\mathrm{N} \times \mathrm{M})$ e vacas mestiças F1 Simental-Nelore e F1 Limousin-Nelore $(\mathrm{SN} \times \mathrm{LN})$ para variáveis relacionadas à eficiência alimentar

\begin{tabular}{|c|c|c|c|c|c|c|}
\hline \multirow[b]{2}{*}{ Variável } & \multicolumn{2}{|c|}{$\begin{array}{l}\text { Nível de probabilidade } \\
\text { para os contrastes }\end{array}$} & \multicolumn{3}{|c|}{$\begin{array}{l}\text { Média de quadrados mínimos } \\
\text { e erros-padrão }\end{array}$} & \multirow[b]{2}{*}{ CV (\%) } \\
\hline & $\mathrm{N} \times \mathrm{M}$ & $\mathrm{SN} \times \mathrm{LN}$ & $\mathrm{N}$ & $\mathrm{SN}$ & $\mathrm{LN}$ & \\
\hline \multicolumn{7}{|c|}{$\begin{array}{l}\text { Eficiência em relação ao consumo anual estimado de MS e } \\
\text { EM da vaca para mantença,lactação e gestação }\end{array}$} \\
\hline $\mathrm{MS} / \mathrm{PD}_{210}, \mathrm{~kg} / \mathrm{kg}$ & 0,0011 & 0,9703 & $18,47 \pm 0,57$ & $15,91 \pm 0,62$ & $15,94 \pm 0,57$ & 12,27 \\
\hline $\mathrm{EM} / \mathrm{PD}_{210}, \mathrm{Mcal} / \mathrm{kg}$ & 0,0010 & 0,9624 & $40,59 \pm 1,26$ & $34,92 \pm 1,37$ & $35,01 \pm 1,26$ & 12,27 \\
\hline $\mathrm{PD}_{210} / \mathrm{EM}, \mathrm{g} / \mathrm{Mcal}$ & 0,0017 & 0,8679 & $25,14 \pm 0,88$ & $28,96 \pm 0,95$ & $25,75 \pm 0,89$ & 11,50 \\
\hline
\end{tabular}

Eficiência em relação ao consumo de EM da vaca para lactação, mantença e gestacão e da energia da perda de peso

\begin{tabular}{llllrr}
$\mathrm{EM} / \mathrm{PD}_{210}, \mathrm{Mcal} / \mathrm{kg}$ & 0,0011 & 0,9723 & $41,45 \pm 1,28$ & $35,71 \pm 1,40$ & $35,77 \pm 1,28$ \\
$\mathrm{PD}_{210} / \mathrm{EM}$, g/Mcal & 0,0018 & 0,8759 & $24,62 \pm 0,86$ & $28,34 \pm 0,93$ & $28,13 \pm 0,96$ \\
\hline
\end{tabular}

* em que: $M S / P D_{210}, \mathrm{~kg} / \mathrm{kg}$ - kg de matéria seca (MS) consumida pela vaca, durante o ano, por kg de bezerro desmamado com 210 dias de idade; $\mathrm{PD}_{210}$ $\mathrm{MS}, \mathrm{g} / \mathrm{kg}$ - gramas de bezerro desmamado com 210 dias de idade por kg de MS consumida pela vaca durante o ano; EM/PD 210 Mcal/kg - Mcal de energia metabolizável (EM) consumida pela vaca durante o ano (acrescida ou não da energia resultante da perda de peso da vaca) por kg de bezerro desmamado com 210 dias de idade; $\mathrm{PD}_{210}$ /EM, g/Mcal - peso de bezerro desmamado com 210 dias de idade, em g, por Mcal de EM consumida pela vaca durante o ano (acrescida ou não da energia resultante da perda de peso da vaca). 
Tabela 5 - Níveis de probabilidade para o erro tipo I associados aos contrastes ortogonais entre progênies de vacas Nelore e mestiças $(\mathrm{N} \times \mathrm{M})$ e de vacas mestiças F1 Simental-Nelore e F1 Limousin-Nelore $(\mathrm{SN} \times \mathrm{LN})$ para variáveis relacionadas à eficiência de ganho de peso

\begin{tabular}{|c|c|c|c|c|c|c|}
\hline \multirow[b]{2}{*}{ Variável } & \multicolumn{2}{|c|}{$\begin{array}{l}\text { Nível de probabilidade } \\
\text { para os contrastes }\end{array}$} & \multicolumn{3}{|c|}{$\begin{array}{c}\text { Média de quadrados mínimos } \\
\text { e erros-padrão }\end{array}$} & \multirow[b]{2}{*}{ CV (\%) } \\
\hline & $\mathrm{N} \times \mathrm{M}$ & $\mathrm{SN} \times \mathrm{LN}$ & $\mathrm{N}$ & $\mathrm{SN}$ & $\mathrm{LN}$ & \\
\hline GPB/PL, g/kg & 0,0654 & 0,0247 & $141,30 \pm 6,86$ & $112,18 \pm 7,46$ & $136,00 \pm 6,86$ & 18,91 \\
\hline $\mathrm{PD}_{210} / \mathrm{PVD}, \mathrm{kg} / \mathrm{kg}$ & 0,0134 & 0,1012 & $0,40 \pm 0,016$ & $0,47 \pm 0,017$ & $0,43 \pm 0,016$ & 13,13 \\
\hline
\end{tabular}

* em que: GPB/PL,g/kg - ganho de peso do bezerro (g) por kg de leite produzido pela vaca; $\mathrm{PD}_{210} / \mathrm{PVD}, \mathrm{kg} / \mathrm{kg}$ - razão entre o peso do bezerro à desmama, aos 210 dias de idade, peso da vaca à desmama.

redução da conversão de leite em peso de bezerro à medida que a produção de leite da vaca aumentou (Tabela 5), sendo maior para as vacas Nelore, que produziram menos leite, intermediária para as vacas LN e mais baixa para as vacas $\mathrm{SN}$, que tiveram produção de leite mais elevada. Os contrastes entre médias indicaram não haver diferença $(\mathrm{P}>0,05)$ entre os bezerros Nelore (progênies de vaca Nelore) e mestiços (progênies de vacas LN e SN). Todavia, de forma coerente, a conversão alimentar dos bezerros filhos das vacas LN (1/2 Brahman $1 / 4$ Limousin $1 / 4$ Nelore) foi melhor $(\mathrm{P}<0,05)$ que a dos bezerros filhos das vacas $\mathrm{SN}$ (3/4 Simental $1 / 4$ Nelore).

Esses resultados estão de acordo com as observações de outros autores, que comprovaram que o aumento do ganho de peso do bezerro e o da produção de leite ocorrem de forma decrescente (rendimentos decrescentes). Assim, Alencar (1989) verificou em vacas Canchim e Nelore divididas em lotes de animais com baixa, média e alta produção, que os bezerros amamentados pelas melhores produtoras de leite apresentaram menor ganho de peso para determinado volume de leite. Nesse trabalho, os bezerros Nelore foram mais eficientes que os Canchim e as conversões foram de 185 e 133 g de ganho por kg de leite, respectivamente.

Melton et al. (1967), considerando todo o período de aleitamento, observaram valores de 5,7; 5,2 e 4,7 kg de leite, respectivamente, por quilograma de ganho de peso do bezerro para animais Angus, Charolês e Hereford e relataram que as vacas Hereford foram as de mais baixo potencial leiteiro.

A relação peso do bezerro/peso da vaca à desmama (PB/PV) tem sido utilizada para comparar a eficiência de vacas de grupos genéticos diferentes. Neste tipo de avaliação, pressupõe-se que o consumo alimentar da vaca, em virtude de suas exigências nutricionais, está diretamente correlacionado ao seu peso corporal. Entretanto, as exigências de mantença e o consumo alimentar de animais de diferentes portes não se relacionam diretamente ao seu peso corporal (elevado à potência 1,0). O NRC (2000) adota o expoente 0,75 , ou seja, (peso vivo) ${ }^{0,75}$, nesses cálculos.
No caso de vacas em lactação, as exigências de nutrientes e o aumento do consumo alimentar associado à lactação relacionam-se ao nível de produção de leite, e não ao peso vivo dos animais. Desta forma, o quociente PB/PV pode não refletir com fidelidade a eficiência de produção da vaca por manter como condição implícita que animais de mesmo peso terão exigências energéticas e consumo alimentar iguais.

A inexatidão da relação PB/PV como medida de eficiência da vaca foi evidenciada por Euclides Filho et al. (1983), que, ao compararem as eficiências de vacas Brown Swiss, F1Brown Swiss-Angus e Angus, encontraram relações $\mathrm{PB} / \mathrm{PV}$ de 0,50; 0,49 e 0,45 para os três grupos, respectivamente. Esses autores concluíram que vacas Brown Swiss e F1 Brown Swiss-Angus superam as Angus quanto a essa característica. Entretanto, ao determinarem o consumo de NDT para a produção de $1 \mathrm{~kg}$ de bezerro desmamado, os resultados se inverteram e os valores foram de 8,91; 8,28 e $7,35 \mathrm{~kg}$ de NDT/kg de bezerro para os três grupos de vacas, respectivamente, comprovando que as vacas Angus foram as mais eficientes.

No Brasil, Euclides Filho et al. (1995) usaram a relação PB/PV para avaliar vacas F1 Fleckvieh-Nelore, F1 Charolês e F1 Chianina-Nelore e concluíram, com base apenas na relação $\mathrm{PB} / \mathrm{PV}=0,41$ verificada para as vacas $\mathrm{F} 1$ FleckviehNelore, que essas vacas foram mais eficientes que as dos dois outros grupos, que apresentaram $\mathrm{PB} / \mathrm{PV}=0,38$.

Neste trabalho, relação $\mathrm{PB} / \mathrm{PV}$ das vacas mestiças foi maior que a das vacas Nelore. A ordenação dos grupos quanto à eficiência, com base no índice PB/PV, coincidiu com aquela obtida para a eficiência em relação à conversão da MS ou EM alimentar em peso de bezerro (Tabela 3).

\section{Conclusões}

Em comparação a vacas Nelore, vacas mestiças convertem com maior eficiência a matéria seca e a energia metabolizável da dieta em ganho de peso de bezerro e peso de bezerro desmamado. A utilização de vacas mestiças Europeu $\times$ 
Nelore pode elevar a eficiência de produção de bezerros de corte no Brasil.

\section{Literatura Citada}

ALENCAR, M.M. Relação entre produção de leite da vaca e desempenho do bezerro nas raças Canchim e Nelore. Revista Brasileira de Zootecnia, v.18, n.2, p.146-156, 1989.

ALENCAR, M.M. Efeitos da produção de leite sobre o desenvolvimento de bezerros Canchim. Revista Brasileira de Zootecnia, v.16, n.1, p.1-13, 1987.

BARROS, C.M.; ERENO, R.L. Avanços em tratamentos hormonais para a inseminação artificial com tempo fixo (IATF) em bovinos de corte. Acta Scientiae Veterinariae, v.32, p.2334, 2004 (supl.).

BOWDEN, D.M. Feed utilization for calf production in the first lactation by 2-years-old F1 crossbred beef cows. Journal of Animal Science, v.55, n.2, p.304-315, 1980.

CALEGARE, L.N.P. Exigências e eficiência energética de vacas de corte Nelore e de cruzamentos Bos taurus x Nelore. Piracicaba: Escola Superior de Agricultura Luiz de Queiroz, 2004. 79p. Dissertação (Mestrado em Agronomia) - Escola Superior de Agricultura Luiz de Queiroz, 2004.

COCHRAN, R.C.; ADAMS, D.C.; WALLACE, J.D. et al. Predicting digestibility of different diets with internal markers: evaluation of four potential markers. Journal of Animal Science, v.63, n.5, p.1476-1483, 1986.

CUNDIFF, L.V.; GREGORY, K.E.; SCHWULST, T. et al. Effects of heterosis on maternal performance and milk production in Hereford, Angus and Shorthorn cattle. Journal of Animal Science, v.38, n.4, p.728-745, 1974.

DAVIS, K.C.; TESS, M.W., KRESS et al. Life cycle evaluation of biological types of beef cattle in a cow-calf range production system: II. Biological and economic performance. Journal of Animal Science, v.72, n.10, p.2591-2598, 1994.

EUCLIDES FILHO, K.; RESTLE, J.; OLSON, T.A. et al. Measures of efficiency of calf production from cows of different size and milking ability. Florida Beef Cattle Research Report, p.13-17, 1983

EUCLIDES FILHO, K.; FIGUEIREDO, G.R.; EUCLIDES, V.P.B. Eficiência de produção de vacas de corte com diferentes potenciais para produção de leite. Pesquisa Agropecuária Brasileira, v.30, n.7, p.1003-1007,1995.

FERRELL, C.L. Maternal and fetal influences on uterine and conceptus development in the cow: I. Growth of tissues of the gravid uterus. Journal of Animal Science, v.69, n.5, p.19451953, 1991

FONTES, C.A.A.; GUIMARÃES, R.F.M.; ALMEIDA, M.I.V. et al. Avaliação do ganho compensatório em novilhos mestiços
Holandês-Gir: consumo e desempenho. Revista Brasileira de Zootecnia, v.36, n.3, p.698-708, 2007.

GREGORY, K.E.; CUNDIFF, L.V. Crossbreeding in beef cattle, evaluation of systems. Journal of Animal Science, v.51, n.5, p.1224-1242, 1980.

GREGORY, K.E.; CUNDIFF, L.V. Breeding programs to use heterosis and breed complementarity. Revista Brasileira de Reprodução Animal, v.23, n.2, p.65-77, 1999.

HOLLOWAY, J.W.; STEPHENS, D.F.; WHITEMN, J.V. et al. Efficiency of production of 2- and 3-year-old Hereford, Hereford $\times$ Holstein and Holstein cows. Journal of Animal Science, v.41, p.855-867, 1975.

JENKINS, T.G.; CUNDIFF, L.V.; FERREL, C.L. Differences among breed crosses of cattle in the conversion of food energy to calf weight during the preweaning interval. Journal of Animal Science, v.69, n.7, p.2762-2769, 1991.

JENKINS, T.G.; FERREL, C.L. Lactation characteristics of nine breeds of cattle fed various quantities of dietary energy. Journal of Animal Science, v.70, n.6, p.1652-1660, 1992.

JENKINS, T.G.; FERREL, C.L. Productivity trough weaning of nine breeds of cattle under varying feed availabilities: I. Initial evaluation. Journal of Animal Science, v.72, n.11, p.2787-2797, 1994.

JENKINS, T.G.; FERREL, C.L. Prewaning efficiency for mature cows of breed crosses from tropically adapted Bos indicus and Bos Taurus and unadapted Bos Taurus breeds. Journal of Animal Science, v.82, n.7, p.1876-1881, 2004.

JENKINS, T.G.; FERREL, C.L. AND ROBERTS, A.J. Lactation and calf weight traits of mature crossbred cows fed varying daily levels of metabolizable energy. Journal of Animal Science, v.78, n.1, p.7-14, 2000.

KLOSTERMAN, E.W.; SANFORD, L.G.; PARKER, C.F. Effect of cow size and condition and ration protein content upon maintenance requirements of mature beef cows. Journal of Animal Science, v.27, p.242-246,1968.

MELTON, A.A.; RIGGS, J.K.; NELSON, L.A. et al. Milk production, composition and calf gains of Angus, Charolais and Hereford cows. Journal of Animal Science, v.26, n.4, p.804-813, 1967.

NATIONAL RESEARCH COUNCIL - NRC. Nutrient requirements of beef cattle. 7.ed. Washington, D.C.: National Academy of Sciences, 2000. 248p.

NEVILLE JR., W.E. Influence of dam's milk production and other factors on 120 and 240 day weight of Hereford calves. Journal of Animal Science, v.21, n.2, p.315-320, 1962.

OLIVEIRA, V.C.; FONTES, C.A.A; SIQUEIRA, J.G. et al. Produção de leite e desempenho dos bezerros de vacas nelores e mestiças. Revista Brasileira de Zootecnia, v.36, n.6, p.2074-2081, 2007 (supl.)

RUTLEDGE, J.J.; ROBISON, O.W.; AHLSCHWEDE, W.T. et al. Milk yield and its influence on 205-day weight of beef calves. Journal of Animal Science, v.33, n.3, p.563-567, 1971. 